\title{
Nonmotor symptoms in Parkinson's disease: classification and management
}

This article was published in the following Dove Press journal:

Journal of Parkinsonism and Restless Legs Syndrome

19 January 2015

Number of times this article has been viewed

\section{Roberto Erro ${ }^{1,2}$ \\ Gabriella Santangelo 3,4 \\ Paolo Barone ${ }^{5}$ \\ Carmine Vitale $e^{4,6}$}

'Sobell Department of Motor Neuroscience and Movement Disorders, UCL Institute of Neurology, London, United Kingdom; ' 2 Dipartimento di Scienze Neurologiche e del Movimento, Università di Verona, Verona, Italy;

${ }^{3}$ Neuropsychology Laboratory, Department of Psychology, Second University of Naples, Caserta, Italy; ${ }^{4}$ IDC Hermitage - Capodimonte, Naples, Italy; ${ }^{5}$ University of Salerno, Center for Neurodegenerative diseases - CEMAND, Salerno, Italy; 'University of Naples "Parthenope," Department of Motor Sciences, Naples, Italy
Correspondence: Roberto Erro Sobell Department of Motor Neuroscience and Movement Disorders, UCL Institute of Neurology,

Queen Square, London, WCIN 3BG, United Kingdom Email erro.roberto@gmail.com

\begin{abstract}
Despite the emphasis on the motor phenotype of Parkinson's disease (PD), it has been increasingly recognized that PD patients experience several nonmotor symptoms (NMS), which have even greater significance when assessed by quality-of-life measures and institutionalization rates. The burden of NMS tends to increase with age and disease severity and, in the very advanced stage of disease, NMS such as urinary problems, drooling, somnolence, psychosis, and dementia dominate the clinical phenotype. Moreover, the dopaminergic treatment used for the motor symptoms of PD can arise or worsen a number of NMS, including orthostatic hypotension, nausea, sleep disturbances, hallucinations, or impulsive compulsive behaviors. Here we review the most common NMS of PD with a focus on their pharmacological management.
\end{abstract}

Keywords: disease management, PD, NMS

\section{Introduction}

Despite the emphasis on the motor phenotype of Parkinson's disease (PD), it has been increasingly recognized that PD patients experience several nonmotor symptoms (NMS), ${ }^{1-5}$ which have even greater significance when assessed by quality-of-life measures and institutionalization rates. ${ }^{6-11}$

Virtually all patients have at least one NMS at the time of diagnosis ${ }^{12,13}$ and some NMS, such as hyposmia and rapid eye movement (REM) sleep behavioral disorder (RBD), can also predate the onset of motor symptoms by several years. ${ }^{14}$ The burden of NMS tends to increase with age and disease severity and, in the very advanced stage of disease, such NMS as urinary problems, drooling, somnolence, psychosis, and dementia dominate the clinical phenotype. ${ }^{15}$ However, there is a marked heterogeneity among patients ${ }^{16}$ and, while the evolution of motor symptoms has been well characterized, little is yet known about the NMS progression. ${ }^{17-19}$ This matter is also complicated by the fact that the dopaminergic treatment used for the motor symptoms of PD can cause or worsen a number of NMS, including orthostatic hypotension $(\mathrm{OH})$, nausea, sleep disturbances, hallucinations, or impulsive compulsive behaviors (ICBs). ${ }^{20-23}$

A recent multicenter survey has shown that the large majority of NMS remain undeclared to health care professionals, probably because patients are either embarrassed or unaware that such NMS are due to $\mathrm{PD} .{ }^{24}$ Use of recently validated NMS screening questionnaire and/or rating scales ${ }^{25,26}$ can facilitate their recognition and management in clinical practice.

NMS have been traditionally grouped into different domains on the basis of a seemingly common pathophysiology, yet not entirely proven. Four main domains are recognized (Table 1), and will be therefore covered accordingly: Autonomic 
Table I Overview of the nonmotor symptoms of PD

\begin{tabular}{|c|c|}
\hline Nonmotor domain & Nonmotor symptoms \\
\hline \multirow[t]{12}{*}{ Autonomic } & Dribbling \\
\hline & Dysphagia \\
\hline & Nausea \\
\hline & Constipation \\
\hline & Urinary frequency \\
\hline & Urinary urgency \\
\hline & Nocturia \\
\hline & Urinary voiding symptoms \\
\hline & Sexual dysfunction \\
\hline & Orthostatic hypotension \\
\hline & Supine (recumbent) hypertension \\
\hline & Excessive sweating \\
\hline \multirow[t]{4}{*}{ Sleep } & Excessive daytime sleepiness \\
\hline & Vivid dreams/REM behavioral disorder \\
\hline & Insomnia \\
\hline & Restless legs syndrome \\
\hline \multirow[t]{5}{*}{ Neuropsychiatric } & Cognitive impairment \\
\hline & Mood disorder, apathy, anhedonia \\
\hline & Psychosis \\
\hline & Hallucinations \\
\hline & Impulsive compulsive behaviors \\
\hline \multirow[t]{3}{*}{ Sensory and other NMS } & Olfactory, visual, and auditory dysfunction \\
\hline & Pain \\
\hline & Fatigue \\
\hline
\end{tabular}

Abbreviations: PD, Parkinson's disease; REM, rapid eye movement; NMS, nonmotor symptoms.

(including gastrointestinal [GI], genitourinary, and cardiovascular symptoms), Sleep, Neuropsychiatric, and Sensory and other symptoms (including pain and fatigue). For each of these nonmotor domains, the most frequent symptoms will be described with a focus, when possible, on their pharmacological management. There is now evidence that nonpharmacological options, including deep brain stimulation, ${ }^{27}$ can ameliorate certain NMS, but this is still a matter of ongoing research and hence will be not covered here.

\section{Autonomic domain}

Autonomic symptoms in PD may be due to the abnormal deposition of $\alpha$-synuclein aggregates in a number of key autonomic regulatory areas (namely, the hypothalamus, parabrachial nucleus, intermediate reticular zone of the medulla, locus coeruleus, and raphe), preganglionic parasympathetic (ie, Edinger-Westphal nucleus and dorsal vagal motor nuclei) and sympathetic regions (ie, intermediolateral cell column), and also in the paravertebral and paravertebral autonomic gangli. ${ }^{28}$ The deposition of $\alpha$-synuclein in such areas can directly cause autonomic symptoms, but it should be noted that antiparkinsonian medications might also play a role. Dopaminergic receptors are widely distributed throughout both the central and peripheral autonomic nervous systems; dopamine lowers systemic blood pressure through vasodilation and decreased catecholamine release and reduces gastric migrating motor complex and gastric motility, whereas it may increase colonic motor activity. ${ }^{28}$ Table 2 provides an overview of the useful investigations to assess the autonomic symptoms.

\section{Gastrointestinal symptoms}

GI symptoms can be very common in $\mathrm{PD}$, with prevalence estimates of $75 \%$ in advanced PD patients..$^{29}$ However, such NMS are very common also in the elderly; therefore, in PD patients they can be due to a combination of the pathological process and normal aging. In $\mathrm{PD}$, they can be classified into upper GI symptoms, among which the most common are sialorrhea, dysphagia, and nausea, and lower GI symptoms, including constipation. ${ }^{30}$

Although excessive drooling has been classically considered an NMS, there is no increased production of saliva as such in PD. Excessive drooling in fact results from inefficient swallowing in PD, and it should be therefore considered more as a motor rather than an autonomic symptom. ${ }^{30} \mathrm{~A}$ great percentage of patients experience dysphagia and show abnormalities on X-ray tests of swallowing. ${ }^{30}$ Although management of dysphagia can be difficult, speech/swallowing therapy can improve symptoms. ${ }^{30}$ Changes in food consistency that reduce the risk of aspiration are sometimes needed. As to excessive drooling, botulinum toxin injections into the salivary glands can ameliorate the sialorrhea, and are relatively free from side effects. ${ }^{31,32}$ Anticholinergic drugs can be tried, ${ }^{30}$ remembering that their side effects, including memory problems, confusion, or blurred vision, are not uncommon with increasing dosage and age of the patients.

Table 2 Overview of the useful investigations to assess autonomic symptoms in PD

\begin{tabular}{ll}
\hline Nonmotor symptoms & Investigations \\
\hline Gastrointestinal & $\begin{array}{l}\text { Swallowing and esophageal motility } \\
\text { (modified barium swallow test) } \\
\text { Gastric emptying studies } \\
\text { Electrogastrogram }\end{array}$ \\
& Colon transit time and anorectal manometry \\
& Urodynamic study and sphincter \\
Urinary symptoms & electromyography \\
& Head-up tilting \\
Cardiovascular symptoms & Valsalva maneuver and pressor stimuli tests \\
& 24-hour blood pressure recording \\
& Meal challenge and exercise test \\
& Heart rate variability \\
& Skin vasomotor reflex \\
& Thermoregulatory sweating test \\
& Skin biopsy \\
\hline
\end{tabular}

Abbreviation: PD, Parkinson's disease. 
Nausea has been reported in drug-naïve PD patients, but is much more common as a side effect of the dopaminergic treatment, especially of dopamine agonists. ${ }^{30}$ In the majority of patients, it is usually transitory, and it can be prevented with domperidone, a peripheral antidopaminergic drug, which increases GI peristalsis and relieves nausea and vomiting.

Constipation is probably the most common GI symptom, with about half of $\mathrm{PD}$ patients experiencing it. ${ }^{29,30}$ Constipation can predate the motor onset of $\mathrm{PD},{ }^{33}$ and some evidence has shown that men who have bowel movements less than once daily compared with two or more times daily have a four times higher risk of PD after a mean time of 10 years. ${ }^{34}$ Severity of constipation increases with advancing disease severity and duration, and can produce complications such as pseudo-obstruction and megacolon. ${ }^{30}$ Drugs used for PD, including the anticholinergics, can exacerbate constipation. ${ }^{30}$ Apart from a well-balanced diet with plenty of fiber (in the range of 20-35 grams daily) and fluid intake, macrogol can be used to treat constipation. ${ }^{30}$

\section{Genitourinary symptoms}

Urinary symptoms (US) are common in PD, with a prevalence of more than $50 \%$ according to screening questionnaires..$^{25,26,29}$ Once again, benign prostate hyperplasia and idiopathic detrusor overactivity often occur in the elderly and can contribute to the US seen in PD. ${ }^{28}$ Interestingly, US likely reflect a combination of underactive D1 receptors activity with possible exacerbation by $\mathrm{D} 2$ receptor stimulation. ${ }^{35}$

US can be categorized into storage symptoms (ie, frequency, urgency, and nocturia) and voiding symptoms (eg, delays in initiating urination, poor or prolonged urine stream). Storage symptoms are common even in the early stage of the disease; troublesome incontinence is usually observed in more advanced PD patients..$^{25,26,29}$ On the other hand, severe voiding symptoms are quite uncommon in PD, at least in the early/middle stages. ${ }^{17,29}$ Medications that work to block or reduce bladder overactivity can be useful in treating storage symptoms ${ }^{36} \mathrm{~A}$ number of medications are available for this aim, including older drugs such as oxybutynin and tolterodine, and newer medications such as solifenacin and darifenacin. ${ }^{36}$ Such drugs are obviously not useful to treat voiding symptoms. ${ }^{37}$ In such cases, bethanechol or botulinum toxin injections may be helpful, but intermittent selfcatheterization is sometimes necessary.

Sexual dysfunction is common in PD, but most data are available only in male patients. ${ }^{19,38}$ Erectile dysfunction is very frequent, with prevalence up to $75 \%{ }^{18,25,29}$
In a recent epidemiological study, erectile dysfunction was also associated with a 2.7 to four-times higher risk of developing PD later in life. ${ }^{39}$ Sexual dysfunction in PD might be caused by multiple factors, including the disease itself or other associated features, such as depression and anxiety. Testosterone deficiency has been implicated. ${ }^{40}$ If sexual drive is normal, both injectable (ie, papaverine, phentolamine, alprostadil) and oral preparations (ie, sildenafil, vardenafil, tadalafil, yohimbine) are available. ${ }^{41,42}$

\section{Cardiovascular symptoms}

Among cardiovascular symptoms, $\mathrm{OH}$ is the most common. Postural hypotensive symptoms in PD have been reported in about half of the patients, but their prevalence increases in the advanced stages. ${ }^{28}$ Symptoms related to $\mathrm{OH}$ can be very heterogeneous. Patients can experience posturally induced dizziness, visual disturbances, transient cognitive impairment, and syncope. OH may also cause fatigue, chest pain, dyspnea, and falls. Food ingestion, exercise, heat, or drugs with hypotensive properties, including some antiparkinsonian agents, can aggravate $\mathrm{OH}$. The management of $\mathrm{OH}$ in patients with PD should start with patient education and nonpharmacological treatment. ${ }^{28,41,42}$ Drug therapy is required for symptomatic patients who do not improve from nonpharmacological management, and consists of alpha1-adrenergic agonists (mainly midodrine) or plasma volume expanders (mainly fludrocortisone)..$^{28,41,42}$

PD patients with $\mathrm{OH}$ may also have supine (recumbent) hypertension, especially at night if they lie entirely supine, with a reversal of the circadian change in blood pressure. ${ }^{28}$ Recumbent hypertension may contribute to ventricular hypertrophy, renal dysfunction and intracerebral hemorrhage. ${ }^{28}$ Antihypertensive drugs can be taken at night, and patients need to be instructed to sleep in a semi-supine position. ${ }^{28}$

\section{Sleep domain}

Sleep symptoms including excessive daytime sleepiness (EDS), vivid dreams, and RBD are very common in PD and affect more than two-thirds of patients. ${ }^{12,17,43}$ Patients can also have restless legs syndrome or sleep disorder breathing, which in turn can affect sleep quality. ${ }^{43}$ Of note, RBD can antedate motor onset by several decades and has been associated with development of cognitive dysfunction in PD. ${ }^{12}$ The pathophysiology of RBD is supposed to involve neuronal degeneration/dysfunction in the brainstem, in particular in the cholinergic regions that regulate muscle atonia during REM sleep. ${ }^{12,20,43}$ Symptoms of RBD are in fact due to a lack of atonia during REM sleep and result in 
dream-enacting behaviors, with possible secondary injuries. There are no clear differences in the frequency of RBD among male and female patients (about 30\% in both), but significant sex differences are associated with its clinical expression, with female PD patients reporting significantly less aggressive behaviors during dreams but more disturbed sleep than male PD patients. ${ }^{44}$ Some medications, including tricyclic antidepressants and serotonin reuptake inhibitors, can worsen RBD symptoms and should be discontinued. ${ }^{45}$ Clonazepam $(0.5-1.0 \mathrm{mg}$, once at night) is the first choice for RBD. It is well tolerated and efficacious in the majority of cases. ${ }^{45}$ If clonazepam is proven ineffective or poorly tolerated, melatonin (3-6 mg, at night) is recommended as second-line therapy. ${ }^{46,47}$ In individual cases, melatonin could be tried first given its favorable side effect profile, but it should be acknowledged that it is far less effective than clonazepam for the treatment of RBD. ${ }^{46,47}$

EDS is likely more frequent than RBD, affecting about $50 \%$ of patients. A combination of the disease process, nocturnal sleep fragmentation, and dopaminergic medications (particularly dopamine agonists) likely determines EDS. ${ }^{48}$ Patients can experience involuntary dozing, with abnormal periods of sleep latency (less than 5 minutes), or sudden sleep attacks. ${ }^{48}$ Improvement of nocturnal sleep can in turn improve EDS, but in some patients specific treatments for EDS are required. Modafinil improves EDS in PD patients, at least on a subjective or behavioral level, and can be therefore considered in PD patients in whom otherwise treatable causes of EDS are absent. ${ }^{46}$

About $20 \%$ of PD patients can also manifest restless legs syndrome, which can cause trouble falling asleep and disrupt sleep quality, if there are associated sleep periodic limbs movements in sleep stages 1 and 2. Low doses of dopamine agonists at bedtime might relieve these symptoms. ${ }^{46}$

\section{Neuropsychiatric domain Cognitive impairment}

Cognitive dysfunction is quite common in $\mathrm{PD}$, and it can occur from the early stages. ${ }^{12,49}$ It has a negative impact on the daily lives of patients and their caregivers ${ }^{6-8}$ and may be associated with subtle functional impairments. ${ }^{50}$ Patients may show executive dysfunctions (planning, concept formation, problem solving), impaired attention and memory, and/or visuospatial dysfunctions. ${ }^{51}$ Whether specific cognitive disturbances are related to different underlying mechanisms is not entirely known, but altered naming or visuospatial functions are considered the strongest predictors of subsequent dementia in PD. ${ }^{52}$ More recently, the construct of Mild Cognitive
Impairment (MCI) has been applied also in PD research. The prevalence of MCI in a meta-analysis of 1346 PD patients was $26 \%,{ }^{53}$ a figure similar to that obtained by the task force commissioned by Movement Disorders Society. ${ }^{54}$ Many risk factors for MCI in PD have been reported, including advanced age, disease duration, and disease severity, ${ }^{54}$ while other features such as side of motor onset have been discarded. ${ }^{55}$ Further NMS, including hallucinations, sleep, and mood disturbances, have been also associated with the development of MCI. ${ }^{56}$ Moreover, subjective memory complaints have been found to be a predictor of MCI. ${ }^{57}$ Since patients with MCI, arguably with posterior cortical profiles, may be at high risk for developing dementia, early identification of patients with MCI is crucial for future neuroprotective trials. To this aim, specific diagnostic criteria for MCI have been recently proposed. ${ }^{58}$

Rivastigmine is effective for the treatment of dementia in PD, whereas there is not enough evidence as far as donepezil, galantamine, and memantine are concerned. ${ }^{46}$ Atomoxetine, a noradrenergic reuptake inhibitor, was reported to improve cognitive function in depressed PD patients. ${ }^{59}$ Rasagiline has shown positive effects on attention and executive functions in nondemented PD patients. ${ }^{60}$ Finally, amantadine has been reported to delay cognitive decline in $\mathrm{PD}{ }^{61}$

\section{Mood disorder, apathy, and anhedonia}

Depressive disorders in PD include major depression, minor depression, dysthymic disorders, and subthreshold depression. ${ }^{62}$ Anxiety can co-occur in some patients ${ }^{62}$ and has been supposed to share, at least in part, the same pathophysiology. ${ }^{63}$ Depression is associated with severe motor symptoms, greater disability, more advanced disease stage, longer disease duration, higher levodopa equivalent dosages, hallucinations, sleep disorders, and dysautonomia. ${ }^{64,65}$ The combination of apathy, anhedonia, and frontal lobe dysfunctions might contribute to the overdiagnosis of depression in PD. ${ }^{66}$ The hypothesis that apathy and depression are in fact two independent NMS of PD was confirmed recently. ${ }^{67}$ Depressive symptoms in PD can be effectively treated by means of dopamine agonists. ${ }^{68}$ There is some evidence for efficacy of selective serotonin and norepinephrine reuptake inhibitors (paroxetine and venlafaxine, respectively) for depression in $\mathrm{PD},{ }^{69}$ while nonpharmacological interventions, including cognitive behavior therapy and repetitive transcranial magnetic stimulation, have been suggested..$^{70-73}$

Apathy is one of the most common NMS of PD, with prevalence rates ranging from $13.9 \%$ to $70 \%{ }^{74}$ Apathy is associated with altered ability of processing inferences about 
other people's emotions and feelings ${ }^{75}$ and with cognitive impairment, particularly dysexecutive syndromes. ${ }^{76,77}$ There are no approved drugs for managing apathy, but since apathy is related to depression and cognitive impairment, pharmacologic agents most frequently administered to apathetic patients include dopaminergic drugs and acetylcholinesterase inhibitors (for a recent review, see reference 74).

Anhedonia is defined as a low ability to experience physical and social pleasure, and its prevalence ranges from $15 \%$ up to $79.7 \%$ in PD patients with depression. ${ }^{78,79}$ It is associated with apathetic or depressive syndromes in PD patients, indicating that reduced hedonic tone may be considered a feature of apathy ${ }^{80}$ and of depression. ${ }^{81,82}$ Conversely, Isella et $\mathrm{al}^{78}$ did not find a relationship between anhedonia, depression, and apathy. Increasing age, apathy, and cognitive dysfunctions were found contributing factors to anhedonia severity. ${ }^{83}$ Anhedonia might be related to cognitive dysfunctions as well. On one hand, no correlations have been found; ${ }^{78}$ on the other hand, we reported that patients with anhedonia performed worse than nondepressed patients without apathy or anhedonia on cognitive tasks tapping visual-constructional and frontal functions. ${ }^{66,82}$ The relationship between anhedonia and frontal dysfunctions might support the idea that anhedonia may depend on frontal lobe dysfunctions arising from alteration of prefrontal dopamine circuits. In this regard, pramipexole and rotigotine have been found to improve anhedonia. $^{83,84}$

\section{Impulsive compulsive behaviors}

A heterogeneous spectrum of ICBs can be seen in PD, ranging from subsyndromal disturbances to frank impulse control disorders (ICDs). ${ }^{85,86}$ They are characterized by the failure to resist an impulse, drive, or temptation to perform an act that is harmful to the person or to others, and are likely under-reported. ${ }^{85,86}$ The most common ICDs include pathological gambling, compulsive buying, hypersexuality, compulsive eating, and medication overuse. Male sex, younger age or younger age at PD onset, personal or family history of substance abuse or ICD, a personality profile characterized by impulsiveness, ${ }^{87,88}$ and cognitive dysfunction, mainly alteration of executive functions, are factors strongly associated with ICDs. ${ }^{89,90}$ Beside these risk factors, treatment with dopamine agonists more than with levodopa has been strongly associated with ICBs/ICDs. ${ }^{85,86,89,91-93}$ Management of ICDs consists of dose reduction or drug discontinuation; ${ }^{94,95}$ results pertaining to the efficacy of amantadine are conflicting. ${ }^{96,97}$ Studies on small samples of PD patients reported reduction of ICDs and impulsivity scores after treatment with selective serotonin reuptake inhibitors, ${ }^{98}$ atypical antipsychotics,,${ }^{99-103}$ and antiepileptic drugs. ${ }^{104-107}$

\section{Sensory domain Olfactory, visual, and auditory dysfunction}

Olfactory dysfunction has been long recognized to be associated with PD, occurring in up to $90 \%$ of cases ${ }^{107}$ and often appearing years prior to the motor symptom onset. ${ }^{108}$ Early onset of anosmia in PD strongly correlates with Braak's findings showing $\alpha$-synuclein deposits in the olfactory structures at the earliest stages of development of PD pathology. ${ }^{109-111}$ Such early involvement of olfactory circuits together with a high prevalence of anosmia in the PD population render smell test a useful and easy-to-administer tool for screening of at-risk subjects. ${ }^{12}$ Smell loss has been also demonstrated in first-degree relatives of patients with inherited forms of $\mathrm{PD}^{113}$ and findings from longitudinal studies showed that smell test may predict future development of PD in asymptomatic family members. ${ }^{108,114}$ Hence, olfactory testing combined with dopamine transporter imaging or other indicators of PD may offer a useful tool to predict risk of PD. Finally, olfactory dysfunction is not stationary in PD patients and deteriorates over time, so hyposmia has been suggested as a marker to assess the disease's progression and the effects of disease-modifying drugs. ${ }^{115}$

Patients with PD may develop a range of visual problems during the course of the disease resulting from abnormalities in visual acuity, color perception, and visual contrast sensitivity. Color and contrast discrimination disturbances have been also suggested as early premotor signs of PD. ${ }^{116,117}$ Furthermore, the severity of these deficits fluctuates throughout the day in association with the dosing schedule of dopaminergic medications. ${ }^{118}$ As the disease progresses, poor visual acuity becomes a common complaint of PD patients, resulting in part from natural aging, ${ }^{119}$ with low contrast acuity being especially affected. ${ }^{120,121}$ Impaired visual acuity also appears to be caused by retinal dopamine deficiency, abnormal eye movements, or poor blinking ${ }^{121}$ and seems to be a risk factor for the development of chronic hallucinations in PD. ${ }^{122}$ Visual deficits in PD are important in influencing global mobility ${ }^{123}$ and are important in influencing quality of life. ${ }^{124}$ Although early in the course of the illness these changes are subtle, as the disease progresses they become clinically evident.

Hearing impairment in the general population increases with age, with $62 \%$ of people having some degree of hearing loss by age $85 .{ }^{124}$ Despite this high prevalence, there is preliminary evidence that hearing impairment can be intrinsic to the NMS spectrum in PD. ${ }^{125,126}$ We have previously showed that 
there is an age-dependent peripheral, unilateral, or bilateral hearing impairment in PD patients, but we could not rule out whether hearing loss is intrinsic to PD or secondary to more complex causative factors. ${ }^{127}$ We hypothesized that natural aging in combination with widespread neuropathologic changes associated with the disease might affect cochlear transmission thus promoting hearing impairment. ${ }^{127}$ More recently, Lai et al investigated in a large retrospective population-based study whether hearing loss was associated with PD and found that the incidence of PD in the hearing loss group was 1.77 -fold higher than that in the nonhearing loss group. ${ }^{128}$ Furthermore, they also suggested that auditory dysfunction might antedate the clinical diagnosis of PD. ${ }^{128}$ Overall, these results support an association between PD and hearing loss, thereby expanding the nonmotor PD phenotype.

\section{Other NMS}

\section{Fatigue}

Fatigue occurs in every stage of $\mathrm{PD}$, with a prevalence ranging from $28 \%$ to $77.6 \% .{ }^{129}$ It may also antecede the onset of motor symptoms in some patients. ${ }^{129}$ Female sex, postural instability/gait difficulties phenotype, depression, anxiety, apathy, sleep disturbances, and autonomic impairment have been associated with fatigue. ${ }^{28,129,130}$ As such, there is a debate on whether fatigue should be considered either a sensory or a neuropsychiatric problem. In view of the fact that clear neuropsychiatric issues can be lacking in PD patients complaining about fatigue, we thought it reasonable to consider fatigue (and pain, as outlined ahead) on their own. The pathophysiology of fatigue in PD is in fact still poorly understood. Several findings suggest that fatigue in PD might have a minor peripheral contribution and a major component due to central mechanisms. ${ }^{131}$ However, it is worth noting that central fatigue may overlap with a number of NMS such as depression, apathy, and sleep problems, thus complicating the understanding of its pathophysiology. Data from neuroimaging studies have suggested that fatigue can be associated with nondopaminergic neural circuits. ${ }^{132}$ However, most studies investigated the effect of dopaminergic drugs on fatigue. There is a suggestion of a beneficial effect of levodopa and pergolide. ${ }^{133,134}$ Moreover, a post hoc analysis of the RECOVER study ${ }^{84}$ found significant improvement on the fatigue item of the Non-Motor Symptoms Scale (NMSS) in the rotigotine group compared with the placebo group, though such benefit was also associated with improvement in depression, apathy, and anhedonia. Finally, a substudy of the ADAGIO study has shown that rasagiline was associated with significantly less progression of fatigue compared with placebo over a 9-month period. ${ }^{135}$ More recently, methylphenidate, a dopamine transporter blocker, at a dose of $10 \mathrm{mg}$ three times a day has been found to improve fatigue in a randomized, placebo-controlled study. ${ }^{136}$

\section{Pain}

Pain is one of the most common NMS in PD. O'Sullivan et al reported that pain was the most frequent NMS reported by PD patients as a first complaint. ${ }^{137}$ Quite intuitively, pain correlates with poorer quality of life; it can also be treatment resistant. The mechanisms underlying pain in $\mathrm{PD}$ are not totally clear. Pain process in PD might be affected at multiple levels, from the transmission of the pain from peripheral structures to the higher centers; in fact, authors have identified four different types of pain in PD. Musculoskeletal pain, determined by rigidity/skeletal deformity, and radicular or neuropathic pain are differentiated by whether or not the pain is described as radiating. ${ }^{138}$ Dystonic pain (often as a complication of dopaminergic medications) and central neuropathic pain are also seen in PD. ${ }^{139}$ As such, the management of pain in PD follows its proper recognition and distinction into these four main types. Peripheral causes of pain can be managed according to the specific situation and with conventional analgesics. Pain associated with dystonia can be related to both $\mathrm{ON}$ and OFF phases, and can be best managed with botulinum toxin injections if rearrangement of dopaminergic therapy cannot be pursued. Central pain can be effectively treated by increasing the dopaminergic load. ${ }^{140}$ Conventional analgesics, opiates, and tricyclic antidepressants are second-line options. ${ }^{140}$

\section{Conclusion}

Poor recognition of NMS in PD affects patients' quality of life and also costs of care; therefore, routine screening for NMS is recommended. The decision as to when to start treatment for NMS and which therapy to use must be taken on an individual basis and depends on several factors, including patient preference, age, the degree of disability, and comorbidities. Future studies are warranted to fully understand the pathophysiology of NMS in PD; this will allow designing specific trials focused on their management.

\section{Author contribution}

RE, GS, PB, and CV made substantial contributions to the conception and design, acquisition of data, and analysis and interpretation of data, drafted the article and revised it critically for intellectual content, and had final approval of the version to be published. 


\section{Disclosure}

The authors report no conflicts of interest in this work.

\section{References}

1. Borek LL, Amick MM, Friedman JH. Non-motor aspects of Parkinson's disease. CNS Spectr. 2006;11(7):541-554.

2. Simuni T, Sethi K. Nonmotor manifestations of Parkinson's disease. Ann Neurol. 2008;64(Suppl 2):S65-S80.

3. Lim SY, Lang AE. The nonmotor symptoms of Parkinson's disease - an overview. Mov Disord. 2010;25 Suppl 1:S123-S130.

4. Postuma RB, Aarsland D, Barone P, et al. Identifying prodromal Parkinson's disease: pre-motor disorders in Parkinson's disease. Mov Disord. 2012;27(5):617-626.

5. The National Institute for Clinical Excellence (NICE). Parkinson's disease: diagnosis and management in primary and secondary care. Clinical guideline 35. 2006. Available at: https://www.nice.org.uk/ guidance/cg35/chapter/introduction. Accessed November 30, 2014.

6. Global Parkinson's Disease Survey Steering Committee. Factors impacting on quality of life in Parkinson's disease: results from an international survey. Mov Disord. 2002;17(1):60-67.

7. Aarsland D, Larsen JP, Tandberg E, Laake K. Predictors of nursing home placement in Parkinson's disease: a population-based, prospective study. J Am Geriatr Soc. 2000;48(8):938-942.

8. Schrag A, Jahanshahi M, Quinn N. What contributes to quality of life in patients with Parkinson's disease? J Neurol Neurosurg Psychiatry. 2000;69(3):308-312.

9. Findley L, Aujla M, Bain PG, et al. Direct economic impact of Parkinson's disease: a research survey in the United Kingdom. Mov Disord. 2003;18(10):1139-1145.

10. Hagell P, Nordling S, Reimer J, Grabowski M, Persson U. Resource use and costs in a Swedish cohort of patients with Parkinson's disease. Mov Disord. 2002;17(6):1213-1220.

11. Pressley JC, Louis ED, Tang MX, et al. The impact of comorbid disease and injuries on resource use and expenditures in parkinsonism. Neurology. 2003;60(1):87-93.

12. Erro R, Santangelo G, Picillo M, et al. Link between non-motor symptoms and cognitive dysfunctions in de novo, drug-naive PD patients. J Neurol. 2012;259(9):1808-1813.

13. Khoo TK, Yarnall AJ, Duncan GW, et al. The spectrum of nonmotor symptoms in early Parkinson disease. Neurology. 2013;80(3):276-281.

14. Tolosa E, Compta Y, Gaig C. The premotor phase of Parkinson's disease. Parkinsonism Relat Disord. 2007;13 Suppl:S2-S7.

15. Ray Chaudhuri K, Rojo JM, Schapira AH, et al. A proposal for a comprehensive grading of Parkinson's disease severity combining motor and non-motor assessments: meeting an unmet need. PLoS One. 2013;8(2):e57221.

16. Erro R, Vitale C, Amboni M, et al. The heterogeneity of early Parkinson's disease: a cluster analysis on newly diagnosed untreated patients. PLoS One. 2013;8(8):e70244.

17. Erro R, Picillo M, Vitale C, et al. Non-motor symptoms in early Parkinson's disease: a 2-year follow-up study on previously untreated patients. J Neurol Neurosurg Psychiatry. 2013;84(1):14-17.

18. Antonini A, Barone P, Marconi R, et al. The progression of non-motor symptoms in Parkinson's disease and their contribution to motor disability and quality of life. J Neurol. 2012;259(12):2621-2631.

19. Picillo M, Erro R, Amboni M, et al. Gender differences in non-motor symptoms in early Parkinson's disease: a 2-years follow-up study on previously untreated patients. Parkinsonism Relat Disord. 2014;20(8): $850-854$

20. Chaudhuri KR, Schapira AH. Non-motor symptoms of Parkinson's disease: dopaminergic pathophysiology and treatment. Lancet Neurol. 2009;8(5):464-474.

21. Kim HJ, Park SY, Cho YJ, et al. Nonmotor symptoms in de novo Parkinson disease before and after dopaminergic treatment. J Neurol Sci. 2009;287(1-2):200-204.
22. Kulisevsky J, García-Sánchez C, Berthier ML, et al. Chronic effects of dopaminergic replacement on cognitive function in Parkinson's disease: a two-year follow-up study of previously untreated patients. Mov Disord. 2000;15(4):613-626.

23. Fera F, Nicoletti G, Cerasa A, et al. Dopaminergic modulation of cognitive interference after pharmacological washout in Parkinson's disease. Brain Res Bull. 2007;74(1-3):75-83.

24. Mitra T, Naidu Y, Martinez-Martin P, et al. The non declaration of non motor symptoms of Parkinson's disease to healthcare professionals. An international survey using the NMSQuest. 6th International Congress on Mental Dysfunctions and other Non-motor Features in Parkinson's disease and Related Disorders. Dresden October, 2008. Park Related Disorders P0II:161.

25. Martinez-Martin P, Schapira AH, Stocchi F, et al. Prevalence of nonmotor symptoms in Parkinson's disease in an international setting; study using nonmotor symptoms questionnaire in 545 patients. Mov Disord. 2007;22(11):1623-1629.

26. Martinez-Martin P, Chaudhuri KR, Rojo-Abuin JM, et al. Assessing the non-motor symptoms of Parkinson's disease: MDS-UPDRS and NMS Scale. Eur J Neurol. Apr 22. doi: 10.1111/ene.12165. [Epub ahead of print].

27. Fasano A, Daniele A, Albanese A. Treatment of motor and non-motor features of Parkinson's disease with deep brain stimulation. Lancet Neurol. 2012;11(5):429-442.

28. Asahina M, Vichayanrat E, Low DA, Iodice V, Mathias CJ. Autonomic dysfunction in parkinsonian disorders: assessment and pathophysiology. J Neurol Neurosurg Psychiatry. 2013;84(6):674-680.

29. Barone P, Antonini A, Colosimo C, et al; PRIAMO study group. The PRIAMO study: A multicenter assessment of nonmotor symptoms and their impact on quality of life in Parkinson's disease. Mov Disord. 2009;24(11):1641-1649.

30. Salat-Foix D, Andrews CN, Meddings J, Suchowersky O. Gastrointestinal symptoms in Parkinson disease: clinical aspects and management. Can J Neurol Sci. 2011;38(4):557-564.

31. Meningaud JP, Pitak-Arnnop P, Chikhani L, Bertrand JC. Drooling of saliva: a review of the etiology and management options. Oral Surg Oral Med Oral Pathol Oral Radiol Endod. 2006;101(1):48-57.

32. Lipp A, Trottenberg T, Schink T, Kupsch A, Arnold G. A randomized trial of botulinum toxin A for treatment of drooling. Neurology. 2003;61(9):1279-1281.

33. Cersosimo MG, Raina GB, Pecci C, et al. Gastrointestinal manifestations in Parkinson's disease: prevalence and occurrence before motor symptoms. J Neurol. 2013;260(5):1332-1338.

34. Abbott RD, Petrovitch H, White LR, et al. Frequency of bowel movements and the future risk of Parkinson's disease. Neurology. 2001;57(3): 456-462.

35. Chaudhuri KR, Healy DG, Schapira AH; National Institute for Clinical Excellence. Non-motor symptoms of Parkinson's disease: diagnosis and management. Lancet Neurol. 2006;5(3):235-245.

36. Kapoor S, Bourdoumis A, Mambu L, Barua J. Effective management of lower urinary tract dysfunction in idiopathic Parkinson's disease. Int J Urol. 2013;20(1):79-84.

37. Campeau L, Soler R, Andersson KE. Bladder dysfunction and parkinsonism: current pathophysiological understanding and management strategies. Curr Urol Rep. 2011;12(6):396-403.

38. Picillo M, Amboni M, Erro R, et al. Gender differences in nonmotor symptoms in early, drug naïve Parkinson's disease. J Neurol. 2013;260(11):2849-2855

39. Gao X, Chen H, Schwarzschild MA, et al. Erectile function and risk of Parkinson's disease. Am J Epidemiol. 2007;166(12):1446-1450.

40. Okun MS, Walter BL, McDonald WM, et al. Beneficial effects of testosterone replacement for the nonmotor symptoms of Parkinson disease. Arch Neurol. 2002;59(11):1750-1753.

41. Perez-Lloret S, Rey MV, Pavy-Le Traon A, Rascol O. Emerging drugs for autonomic dysfunction in Parkinson's disease. Expert Opin Emerg Drugs. 2013;18(1):39-53. 
42. Sprenger F, Poewe W. Management of motor and non-motor symptoms in Parkinson's disease. CNS Drugs. 2013;27(4):259-272.

43. Louter M, Aarden WC, Lion J, Bloem BR, Overeem S. Recognition and diagnosis of sleep disorders in Parkinson's disease. J Neurol. 2012; 259(10):2031-2040.

44. Rolinski M, Szewczyk-Krolikowski K, Tomlinson PR, et al. REM sleep behaviour disorder is associated with worse quality of life and other non-motor features in early Parkinson's disease. J Neurol Neurosurg Psychiatry. 2014;85(5):560-566.

45. Chahine LM, Daley J, Horn S, et al. Association between dopaminergic medications and nocturnal sleep in early-stage Parkinson's disease. Parkinsonism Relat Disord. 2013;19(10):859-863.

46. Seppi K, Weintraub D, Coelho M, et al. The Movement Disorder Society Evidence-Based Medicine Review Update: Treatments for the non-motor symptoms of Parkinson's disease. Mov Disord. 2011; 26 Suppl 3:S42-S80.

47. Kunz D, Mahlberg R. A two-part, double-blind, placebo-controlled trial of exogenous melatonin in REM sleep behaviour disorder. J Sleep Res. 2010;19(4):591-596.

48. Chaudhuri KR, Logishetty K. Dopamine receptor agonists and sleep disturbances in Parkinson's disease. Parkinsonism Relat Disord. 2009; 15(Suppl 4):S101-S104.

49. Hely MA, Reid WG, Adena MA, Halliday GM, Morris JG. The Sydney multicenter study of Parkinson's disease: the inevitability of dementia at 20 years. Mov Disord. 2008;23(6):837-844.

50. Weintraub D, Moberg PJ, Duda JE, Katz IR, Stern MB. Effect of psychiatric and other nonmotor symptoms on disability in Parkinson's disease. J Am Geriatr Soc. 2004;52(5):784-788.

51. Svenningsson P, Westman E, Ballard C, Aarsland D. Cognitive impairment in patients with Parkinson's disease: diagnosis, biomarkers, and treatment. Lancet Neurol. 2012;11(8):697-707.

52. Williams-Gray CH, Evans JR, Goris A, et al. The distinct cognitive syndromes of Parkinson's disease: 5 year follow-up of the CamPaIGN cohort. Brain. 2009;132(Pt 11):2958-2969.

53. Aarsland D, Bronnick K, Williams-Gray C, et al. Mild cognitive impairment in Parkinson disease: a multicenter pooled analysis. Neurology. 2010;75(12):1062-1069.

54. Litvan I, Aarsland D, Adler CH, et al. MDS Task Force on mild cognitive impairment in Parkinson's disease: critical review of PD-MCI. Mov Disord. 2011;26(10):1814-1824.

55. Erro R, Santangelo G, Picillo M, et al. Side of onset does not influence cognition in newly diagnosed untreated Parkinson's disease patients. Parkinsonism Relat Disord. 2013;19(2):256-259.

56. Aarsland D, Taylor JP, Weintraub D. Psychiatric issues in cognitive impairment. Mov Disord. 2014;29(5):651-662.

57. Erro R, Santangelo G, Barone P, et al. Do subjective memory complaints herald the onset of mild cognitive impairment in Parkinson disease? J Geriatr Psychiatry Neurol. 2014;27(4):276-281.

58. Litvan I, Goldman JG, Tröster AI, et al. Diagnostic criteria for mild cognitive impairment in Parkinson's disease: Movement Disorder Society Task Force guidelines. Mov Disord. 2012;27(3):349-356.

59. Weintraub D, Mavandadi S, Mamikonyan E, et al. Atomoxetine for depression and other neuropsychiatric symptoms in Parkinson disease. Neurology. 2010;75(5):448-455.

60. Hanagasi HA, Gurvit H, Unsalan P, et al. The effects of rasagiline on cognitive deficits in Parkinson's disease patients without dementia: a randomized, double-blind, placebo-controlled, multicenter study. Mov Disord. 2011;26(10):1851-1858.

61. Inzelberg R, Bonuccelli U, Schechtman E, et al. Association between amantadine and the onset of dementia in Parkinson's disease. Mov Disord. 2006;21(9):1375-1379.

62. Tan LC. Mood disorders in Parkinson's disease. Parkinsonism Relat Disord. 2012;18(Suppl 1):S74-S76.

63. Erro R, Pappatà S, Amboni M, et al. Anxiety is associated with striatal dopamine transporter availability in newly diagnosed untreated Parkinson's disease patients. Parkinsonism Relat Disord. 2012;18(9):1034-1038.
64. Starkstein SE, Preziosi TJ, Berthier ML, Bolduc PL, Mayberg HS, Robinson RG. Depression and cognitive impairment in Parkinson's disease. Brain. 1989;112(Pt 5):1141-1153.

65. Dissanayaka NNW, Sellbach A, Silburn PA, O'Sullivan JD, Marsh R, Mellick GD. Factors associated with depression in Parkinson's disease. J Affect Disord. 2011;132(1-2):82-88.

66. Santangelo G, Vitale C, Trojano L, et al. Relationship between depression and cognitive dysfunctions in Parkinson's disease without dementia. J Neurol. 2009;256(4):632-638.

67. Varanese S, Perfetti B, Ghilardi MF, Di Rocco A. Apathy, but not depression, reflects inefficient cognitive strategies in Parkinson's disease. PLoS One. 2011;6(3):e17846.

68. Barone P, Poewe W, Albrecht S, et al. Pramipexole for the treatment of depressive symptoms in patients with Parkinson's disease: a randomised, double-blind, placebo-controlled trial. Lancet Neurol. 2010;9(6):573-580.

69. Skapinakis P, Bakola E, Salanti G, Lewis G, Kyritsis AP, Mavreas V. Efficacy and acceptability of selective serotonin reuptake inhibitors for the treatment of depression in Parkinson's disease: a systematic review and meta-analysis of randomized controlled trials. BMC Neurol. 2010;10:49

70. Dobkin RD, Menza M, Allen LA, et al. Cognitive-behavioral therapy for depression in Parkinson's disease: a randomized, controlled trial. Am J Psychiatry. 2011;168(10):1066-1074.

71. Pal E, Nagy F, Aschermann Z, Balazs E, Kovacs N. The impact of left prefrontal repetitive transcranial magnetic stimulation on depression in Parkinson's disease: a randomized, double-blind, placebo-controlled study. Mov Disord. 2010;25(14):2311-2317.

72. Boggio PS, Fregni F, Bermpohl F, et al. Effect of repetitive TMS and fluoxetine on cognitive function in patients with Parkinson's disease and concurrent depression. Mov Disord. 2005;20(9): $1178-1184$

73. Fregni F, Santos CM, Myczkowski ML, et al. Repetitive transcranial magnetic stimulation is as effective as fluoxetine in the treatment of depression in patients with Parkinson's disease. J Neurol Neurosurg Psychiatry. 2004;75(8):1171-1174.

74. Santangelo G, Trojano L, Barone P, Errico D, Grossi D, Vitale C. Apathy in Parkinson's disease: diagnosis, neuropsychological correlates, pathophysiology and treatment. Behav Neurol. 2013;27(4):501-513.

75. Santangelo G, Vitale C, Trojano L, et al. Neuropsychological correlates of theory of mind in patients with early Parkinson's disease. Mov Disord. 2012;27(1):98-105.

76. Grossi D, Santangelo G, Barbarulo AM, et al. Apathy and related executive syndromes in dementia associated with Parkinson's disease and in Alzheimer's disease. Behav Neurol. 2013;27(4):515-522.

77. Santangelo G, Vitale C, Trojano L, et al. Relationship between apathy and cognitive dysfunctions in de novo untreated Parkinson's disease: a prospective longitudinal study. Eur J Neurol. May 22. doi: 10.1111/ ene.12467. [Epub ahead of print].

78. Isella V, Iurlaro S, Piolti R, et al. Physical anhedonia in Parkinson's disease. J Neurol Neurosurg Psychiatry. 2003;74(9):1308-1311.

79. Matsui K, Tachibana H, Yamanishi T, et al. Clinical correlates of anhedonia in patients with Parkinson's disease. Clin Neurol Neurosurg. 2013;115(12):2524-2527.

80. Pluck GC, Brown RG. Apathy in Parkinson's disease. J Neurol Neurosurg Psychiatry. 2002;73(6):636-642.

81. Lemke MR, Brecht HM, Koester J, Reichmann H. Effects of the dopamine agonist pramipexole on depression, anhedonia and motor functioning in Parkinson's disease. J Neurol Sci. 2006;248(1-2):266-270.

82. Santangelo G, Morgante L, Savica R, et al; PRIAMO Study Group. Anhedonia and cognitive impairment in Parkinson's disease: Italian validation of the Snaith-Hamilton Pleasure Scale and its application in the clinical routine practice during the PRIAMO study. Parkinsonism Relat Disord. 2009;15(8):576-581.

83. Reichmann H, Odin P, Brecht HM, Köster J, Kraus PH. Changing dopamine agonist treatment in Parkinson's disease: experiences with switching to pramipexole. J Neural Transm Suppl. 2006;(71):17-25. 
84. Ray Chaudhuri K, Martinez-Martin P, Antonini A, et al. Rotigotine and specific non-motor symptoms of Parkinson's disease: post hoc analysis of RECOVER. Parkinsonism Relat Disord. 2013;19(7):660-665.

85. Ceravolo R, Frosini D, Rossi C, Bonuccelli U. Impulse control disorders in Parkinson's disease: definition, epidemiology, risk factors, neurobiology and management. Parkinsonism Relat Disord. 2009; 15 Suppl 4:S111-S115.

86. Djamshidian A, Averbeck BB, Lees AJ, O’Sullivan SS. Clinical aspects of impulsive compulsive behaviours in Parkinson's disease. J Neurol Sci. 2011;310(1-2):183-188.

87. Lim SY, Tan ZK, Ngam PI, et al. Impulsive-compulsive behaviors are common in Asian Parkinson's disease patients: assessment using the QUIP. Parkinsonism Relat Disord. 2011;17(10):761-764.

88. Antonini A, Siri C, Santangelo G, et al. Impulsivity and compulsivity in drug-naïve patients with Parkinson's disease. Mov Disord. 2011;26(3) 464-468.

89. Santangelo G, Barone P, Trojano L, Vitale C. Pathological gambling in Parkinson's disease. A comprehensive review. Parkinsonism Relat Disord. 2013;19(7):645-653.

90. Vitale C, Santangelo G, Trojano L, et al. Comparative neuropsychological profile of pathological gambling, hypersexuality, and compulsive eating in Parkinson's disease. Mov Disord. 2011;26(5):830-836.

91. Weintraub D, Siderowf AD, Potenza MN, et al. Association of dopamine agonists use with impulse control disorders in Parkinson's disease. Arch Neurol. 2006;63(7):969-973.

92. Voon V, Thomsen T, Miyasaki JM, et al. Factors associated with dopaminergic drug-related pathological gambling in Parkinson disease. Arch Neurol. 2007;64(2):212-216.

93. Voon V, Sohr M, Lang AE, et al. Impulse control disorders in Parkinson disease: a multicenter case - control study. Ann Neurol. 2011;69(6):986-996.

94. Driver-Dunckley E, Samanta J, Stacy M. Pathological gambling associated with dopamine agonist therapy in Parkinson's disease. Neurology. 2003;61(3):422-423.

95. Dodd ML, Klos KJ, Bower JH, Geda YE, Josephs KA, Ahlskog JE. Pathological gambling caused by drugs used to treat Parkinson disease. Arch Neurol. 2005;62(9):1377-1381.

96. Weintraub D, Sohr M, Potenza MN, et al. Amantadine use associated with impulse control disorders in Parkinson disease in cross-sectional study. Ann Neurol. 2010;68(6):963-968.

97. Thomas A, Bonanni L, Gambi F, Di Iorio A, Onofrj M. Pathological gambling in Parkinson disease is reduced by amantadine. Ann Neurol 2010;68(3):400-404

98. Grant JE, Potenza MN. Impulse control disorders: clinical characteristics and pharmacological management. Ann Clin Psychiatry. 2004; 16(1):27-34.

99. Fong T, Kalechstein A, Bernhard B, Rosenthal R, Rugle L. A double-blind, placebo-controlled trial of olanzapine for the treatment of video poker pathological gamblers. Pharmacol Biochem Behav 2008;89(3):298-303.

100. Seedat S, Kesler S, Niehaus DJ, Stein DJ. Pathological gambling behaviour: emergence secondary to treatment of Parkinson's disease with dopaminergic agents. Depress Anxiety. 2000;11(4):185-186.

101. Bostwick JM, Hecksel KA, Stevens SR, Bower JH, Ahlskog JE. Frequency of new-onset pathologic compulsive gambling or hypersexuality after drug treatment of idiopathic Parkinson disease. Mayo Clin Proc. 2009;84(4):310-316.

102. Rotondo A, Bosco D, Plastino M, Consoli A, Bosco F. Clozapine for medication-related pathological gambling in Parkinson disease. Mov Disord. 2010;25(12):1994-1995.

103. Sevincok L, Akoglu A, Akyol A. Quetiapine in a case with Parkinson disease and pathological gambling. J Clin Psychopharmacol. 2007;27(1):107-108.

104. Hicks CW, Pandya MM, Itin I, Fernandez HH. Valproate for the treatment of medication-induced impulse-control disorders in three patients with Parkinson's disease. Parkinsonism Relat Disord. 2011;17(5): 379-381.
105. Bermejo PE. Topiramate in managing impulse control disorders in Parkinson's disease. Parkinsonism Relat Disord. 2008;14(5): 448-449.

106. Bermejo PE, Ruiz-Huete C, Anciones B. Zonisamide in managing impulse control disorders in Parkinson's disease. J Neurol. 2010; 257(10):1682-1685.

107. Doty RL, Deems DA, Stellar S. Olfactory dysfunction in parkinsonism: a general deficit unrelated to neurologic signs, disease stage, or disease duration. Neurology. 1988;38(8):1237-1244.

108. Ross GW, Petrovitch H, Abbott RD, et al. Association of olfactory dysfunction with risk for future Parkinson's disease. Ann Neurol. 2008;63(2):167-173

109. Braak H, Ghebremedhin E, Rüb U, Bratzke H, Del Tredici K. Stages in the development of Parkinson's disease-related pathology. Cell Tissue Res. 2004;318(1):121-134.

110. Wolters ECh, Braak H. Parkinson's disease: premotor clinico-pathological correlations. J Neural Transm Suppl. 2006;(70):309-319.

111. Doty RL. The olfactory vector hypothesis of neurodegenerative disease: is it viable? Ann Neurol. 2008;63(1):7-15

112. Picillo M, Pellecchia MT, Erro R, et al. The use of University of Pennsylvania Smell Identification Test in the diagnosis of Parkinson's disease in Italy. Neurol Sci. 2014;35(3):379-383.

113. Markopoulou K, Larsen KW, Wszolek EK, et al. Olfactory dysfunction in familial parkinsonism. Neurology. 1997;49(5):1262-1267.

114. Ponsen MM, Stoffers D, Wolters ECh, Booij J, Berendse HW. Olfactory testing combined with dopamine transporter imaging as a method to detect prodromal Parkinson's disease. J Neurol Neurosurg Psychiatry. 2010;81(4):396-399.

115. Berendse HW, Roos DS, Raijmakers P, Doty RL. Motor and non-motor correlates of olfactory dysfunction in Parkinson's disease. $J$ Neurol Sci. 2011;310(1-2):21-24.

116. Büttner T, Kuhn W, Müller T, Patzold T, Heidbrink K, Przuntek H. Distorted color discrimination in 'de novo' parkinsonian patients. Neurology. 1995;45(2):386-387

117. Postuma RB, Lang AE, Massicotte-Marquez J, Montplaisir J. Potential early markers of Parkinson disease in idiopathic REM sleep behavior disorder. Neurology. 2006;66(6):845-851.

118. Almer Z, Klein KS, Marsh L, Gerstenhaber M, Repka MX. Ocular motor and sensory function in Parkinson's disease. Ophthalmology. 2012;119(1):178-182.

119. Repka MX, Claro MC, Loupe DN, Reich SG. Ocular motility in Parkinson's disease. J Pediatr Ophthalmol Strabismus. 1996;33(3): 144-147.

120. Jones RD, Donaldson IM. Fractionation of visuoperceptual dysfunction in Parkinson's disease. J Neurol Sci. 1995;131(1):43-50.

121. Jones RD, Donaldson IM, Timmings PL. Impairment of high-contrast visual acuity in Parkinson's disease. Mov Disord. 1992;7(3):232-238.

122. Matsui H, Udaka F, Tamura A, et al. Impaired visual acuity as a risk factor for visual hallucinations in Parkinson's disease. J Geriatr Psychiatry Neurol. 2006;19(1):36-40.

123. Diederich NJ, Raman R, Leurgans S, Goetz CG. Progressive worsening of spatial and chromatic processing deficits in Parkinson disease. Arch Neurol. 2002;59(8):1249-1252.

124. Abutan BB, Hoes AW, Van Dalsen CL, Verschuure J, Prins A. Prevalence of hearing impairment and hearing complaints in older adults: a study in general practice. Fam Pract. 1993;10(4):391-395.

125. Gawel MJ, Das P, Vincent S, Rose FC. Visual and auditory evoked responses in patients with Parkinson's disease. J Neurol Neurosurg Psychiatry. 1981;44:227-232.

126. Fradis M, Samet A, Ben-David J, et al. Brainstem auditory evoked potentials to different stimulus rates in parkinsonian patients. Eur Neurol. 1988;28(4):181-186.

127. Vitale C, Marcelli V, Allocca R, et al. Hearing impairment in Parkinson's disease: expanding the nonmotor phenotype. Mov Disord. 2012;27(12):1530-1535

128. Lai SW, Liao KF, Lin CL, Lin CC, Sung FC. Hearing loss may be a non-motor feature of Parkinson's disease in older people in Taiwan. Eur J Neurol. 2014;21(5):752-757. 
129. Hagell $\mathrm{P}$, Brundin L. Towards an understanding of fatigue in Parkinson disease. J Neurol Neurosurg Psychiatry. 2009;80(5):489-492.

130. Beiske AG, Loge JH, Hjermstad MJ, Svensson E. Fatigue in Parkinson's disease: prevalence and associated factors. Mov Disord. 2010;25(14):2456-2460.

131. Berardelli A, Conte A, Fabbrini G, et al. Pathophysiology of pain and fatigue in Parkinson's disease. Parkinsonism Relat Disord. 2012; 18 Suppl 1:S226-S228.

132. Pavese N, Metta V, Bose SK, Chaudhuri KR, Brooks DJ. Fatigue in Parkinson's disease is linked to striatal and limbic serotonergic dysfunction. Brain. 2010;133(11):3434-3443.

133. Lou JS, Kearns G, Benice T, Oken B, Sexton G, Nutt J. Levodopa improves physical fatigue in Parkinson's disease: a double-blind, placebo-controlled, crossover study. Mov Disord. 2003;18(10): $1108-1114$.

134. Abe K, Takanashi M, Yanagihara T, Sakoda S. Pergolide mesilate may improve fatigue in patients with Parkinson's disease. Behav Neurol. 2001-2002;13(3-4):117-121.

135. Stocchi F; ADAGIO investigators. Benefits of treatment with rasagiline for fatigue symptoms in patients with early Parkinson's disease. Eur J Neurol. 2014;21(2):357-360.
136. Mendonça DA, Menezes K, Jog MS. Methylphenidate improves fatigue scores in Parkinson disease: a randomized controlled trial. Mov Disord. 2007;22(14):2070-2076.

137. O'Sullivan SS, Williams DR, Gallagher DA, Massey LA, SilveiraMoriyama L, Lees AJ. Nonmotor symptoms as presenting complaints in Parkinson's disease: a clinicopathological study. Mov Disord. 2008;23(1):101-106.

138. Beiske AG, Loge JH, Rønningen A, Svensson E. Pain in Parkinson's disease: Prevalence and characteristics. Pain. 2009;141(1-2): $173-177$.

139. Nègre-Pagès L, Regragui W, Bouhassira $\mathrm{D}$, Grandjean $\mathrm{H}$, Rascol $\mathrm{O}$; DoPaMiP Study Group. Chronic pain in Parkinson's disease: the cross-sectional French DoPaMiP survey. Mov Disord. 2008;23(10): 1361-1369.

140. Ford B. Pain in Parkinson's disease. Mov Disord. 2010;25 Suppl 1: S98-S103.
Journal of Parkinsonism \& Restless Legs Syndrome

\section{Publish your work in this journal}

Journal of Parkinsonism and Restless Legs Syndrome is an online, open access, peer-reviewed journal. The journal publishes review articles, historical reviews, original research articles, case reports, letters to the editor, clinical teaching cases, neuroradiology highlights, neuropathology highlights, neuropsychiatry highlights, autobiographies, conference

\section{Dovepress}

proceedings, abstracts and book reviews. The manuscript management system is completely online and includes a very quick and fair peerreview system, which is all easy to use. Visit http://www.dovepress.com/ testimonials.php to read real quotes from published authors. 